\title{
Asymptomatic Deep Vein Thrombosis in a Patient with Major Depressive Disorder
}

\author{
Takuto Ishida, 1,2 Takeshi Katagiri, ${ }^{1,2}$ Hiroyuki Uchida, ${ }^{2,3}$ Takefumi Suzuki, $^{2}$ \\ Koichiro Watanabe, ${ }^{2}$ and Masaru Mimura ${ }^{2}$ \\ ${ }^{1}$ Department of Psychiatry, Sakuragaoka Memorial Hospital, 1-1-1 Renkouji, Tama-shi, Tokyo 206-0021, Japan \\ ${ }^{2}$ Department of Neuropsychiatry, Keio University School of Medicine, 35 Shinanomachi, Shinjuku-ku, Tokyo 160-8582, Japan \\ ${ }^{3}$ Geriatric Mental Health Program, Centre for Addiction and Mental Health, Queen Street Site, 1001 Queen Street West, \\ Toronto, ON, Canada M6J $1 \mathrm{H} 4$ \\ Correspondence should be addressed to Takuto Ishida, t_ishi_2750@yahoo.co.jp
}

Received 30 July 2012; Accepted 5 September 2012

Academic Editors: S. Cortese and M. Kellner

Copyright () 2012 Takuto Ishida et al. This is an open access article distributed under the Creative Commons Attribution License, which permits unrestricted use, distribution, and reproduction in any medium, provided the original work is properly cited.

\begin{abstract}
Pulmonary embolism is a serious, life-threatening condition and most commonly derives from deep vein thrombosis of the lower extremities. Once deep vein thrombosis (DVT) reaches a proximal vein (i.e., popliteal vein or higher), pulmonary embolism reportedly occurs in up to $50 \%$ of patients. Case Presentation. We report on an inpatient with major depressive disorder in a catatonic state in whom an asymptomatic proximal deep vein thrombosis of $11 \times 70 \mathrm{~mm}$ was detected through routine screening, using doppler ultrasound scanning. Anticoagulant therapy was immediately started and continued for three months, which resulted in resolution of the deep vein thrombosis. Discussion. To our knowledge, this is the first description of asymptomatic proximal DVT that was detected in a psychiatric inpatient setting. In light of the reported causal relationship between DVT and pulmonary embolism, screening for DVT can be of high clinical value in patients with psychiatric disorders, especially when their physical activity is highly compromised.
\end{abstract}

\section{Introduction}

Pulmonary embolism (PE) is a serious, life-threatening condition and most commonly derives from deep vein thrombosis (DVT) of the lower extremities [1]. Most DVTs originate in the calves, and $80 \%$ of distal DVTs are known to resolve spontaneously [1]. However, once DVTs reach a proximal vein (i.e., popilteal vein or higher), PE reportedly occurs in up to $50 \%$ of patients [1]. Therefore, in order to prevent $\mathrm{PE}$, it is critically important to detect DVTs of the lower extremities.

DVTs have been reported to occur in up to $10-40 \%$ of hospitalized patients with a physical morbidity [2], and approximately $70-80 \%$ of such DVTs are asymptomatic [3]. Although there has been no systematic survey on the incidence of DVTs in psychiatric settings, it is very likely to be high, considering the lowered physical activity level of patients with psychiatric disorders. In our institution, we have therefore been conducting a routine screening of
DVTs for inpatients who have been bedridden (i.e., deeply sedated or catatonic) for $\geq 2$ days since October, 2009. In this screening, a D-dimer level is measured for all these patients when they are ambulant, and doppler ultrasound scanning is performed when the level is higher than $0.5 \mu \mathrm{g} / \mathrm{dL}$.

Here, we report on a patient with major depressive disorder in whom an asymptomatic proximal DVT was detected through routine screening.

\section{Case Presentation}

A 65-year-old woman with a 13-year history of major depressive disorder was admitted to our hospital because of depressive mood, appetite loss, insomnia, and psychomotor retardation. She had no past history of any physical illness. Since she did not respond to paroxetine $40 \mathrm{mg} /$ day or mirtazapine $45 \mathrm{mg} /$ day, intravenous administration of clomipramine $25 \mathrm{mg}$ /day was started on Day 7 with hydration of $1500 \mathrm{~mL} /$ day. However, she did not 
show any improvement, and she developed a catatonic state on Day 21. Since she had been laying on a bed all day without any voluntary movement, routine screening for DVTs was performed on Day 28; her plasma D-dimer level was elevated at $3.20 \mu \mathrm{g} / \mathrm{dL}$, and doppler ultrasound scanning revealed a $11 \times 70 \mathrm{~mm}$ thrombosis in her left femoral vein. Anticoagulant therapy, consisting of warfarin $1 \mathrm{mg} /$ day and subcutaneous injection of unfractionated heparin $10000 \mathrm{IU} /$ day, was started, and the dose of warfarin was adjusted to achieve 2.0-3.0 in International Normalized Ratio. Warfarin was continued for three months, which resulted in resolution of the DVT. Her depressive symptoms were then successfully treated with electroconvulsive therapy.

\section{Discussion}

To our knowledge, this is the first description of asymptomatic proximal DVT that was detected in a psychiatric inpatient setting. Catatonia is a common manifestation of psychiatric illnesses and characterized by a lack of voluntary physical activity. Considering that this patient did not have any other DVT risk factors, a lack of physical activity caused by catatonia would be expected to have triggered a development of DVT. Consistent with this, 22 cases of PE in catatonic patients were previously reported [4]. Several guidelines encouraged prophylactic interventions for the prevention of DVTs for hospitalized patients [5], which has not yet been addressed in psychiatric settings. Although there has been no systematic survey on the incidence of DVTs in psychiatric settings, it is likely to be high in patients with psychiatric illnesses, given their physical inactivity and the sedative effects of psychotropics. In fact, it was reported that antipsychotic usage was a risk factor for DVT [6]. Furthermore, approximately $70-80 \%$ of DVTs are clinically silent or asymptomatic [3], which underscores the need of screening for DVTs in high-risk patients. These findings suggest that screening for DVTs can be of high clinical value to effectively detect and treat DVTs in patients with psychiatric disorders, especially when their physical activity is highly compromised.

\section{Abbreviations}

DVT: Deep vein thrombosis

INR: International normalized ratio

PE: Pulmonary embolism.

\section{Consent}

Written informed consent was obtained from the patient for publication of this paper and any accompanying images. A copy of the written consent is available for review by the Series Editor of this journal.

\section{Conflict of Interests}

T. Ishida has received paper fees from Dainippon Sumitomo Pharma within the past 5 years. H. Uchida has received grants from Pfizer, speaker's honoraria from Otsuka Pharmaceutical, Janssen Pharmaceutical, and Shionogi and paper fees from Dainippon Sumitomo Pharma within the past 5 years. T. Suzuki has received grants from Kanae Foundation and Mochida Memorial Foundation, and manuscript fees form Dainippon Sumitomo Pharma and Kyowa Hakko Kirin within the past 5 years. K. Watanabe has received grants or consultant fees from Dainippon Sumitomo Pharma, Eli Lilly, GlaxoSmithKline, Janssen Pharmaceutical, and Pfizer and received speaker's honoraria from Astellas Pharma, Dainippon Sumitomo Pharma, Eli Lilly, GlaxoSmithKline, Janssen Pharmaceutical, Meiji, Otsuka Pharmaceutical, Pfizer and Yoshitomiyakuhin within the past 5 years. M. Mimura has received grants or consultant fees from Eisai, Astellas Pharma, GlaxoSmithKline and Meiji, and received speaker's honoraria from Astellas Pharma, Dainippon Sumitomo Pharma, Eli Lilly, GlaxoSmithKline, Janssen Pharmaceutical, Meiji, Otsuka Pharmaceutical, Pfizer, and Yoshitomiyakuhin within the past 5 years. Other authors have nothing to disclose.

\section{Authors' Contribution}

All authors listed have participated in drafting the paper or revising it critically for important intellectual content and read and approved the final version of the paper.

\section{Acknowledgments}

The authors gratefully acknowledge Drs. Satoru Iwashita and Mizuki Oka for their continuous support and valuable advice.

\section{References}

[1] C. Kearon, "Natural history of venous thromboembolism," Circulation, vol. 107, no. 23, pp. I22-I30, 2003.

[2] J. Attia, J. G. Ray, D. J. Cook, J. Douketis, J. S. Ginsberg, and W. H. Geerts, "Deep vein thrombosis and its prevention in critically ill adults," Archives of Internal Medicine, vol. 161, no. 10, pp. 1268-1279, 2001.

[3] F. Dentali, J. D. Douketis, M. Gianni, W. Lim, and M. A. Crowther, "Meta-analysis: anticoagulant prophylaxis to prevent symptomatic venous thromboembolism in hospitalized medical patients," Annals of Internal Medicine, vol. 146, no. 4, pp. 278-288, 2007.

[4] W. V. McCall, S. C. Mann, F. E. Shelp, and S. N. Caroff, "Fatal pulmonary embolism in the catatonic syndrome: two case reports and a literature review," Journal of Clinical Psychiatry, vol. 56, no. 1, pp. 21-25, 1995.

[5] W. H. Geerts, D. Bergqvist, G. F. Pineo et al., "Prevention of venous thromboembolism: American College of Chest Physicians Evidence-Based Clinical Practice Guidelines (8th edition)," Chest, vol. 133, no. 6, supplement, pp. 381S-453S, 2008.

[6] C. Parker, C. Coupland, and J. Hippisley-Cox, "Antipsychotic drugs and risk of venous thromboembolism: nested casecontrol study," British Medical Journal, vol. 341, p. c4245, 2010. 


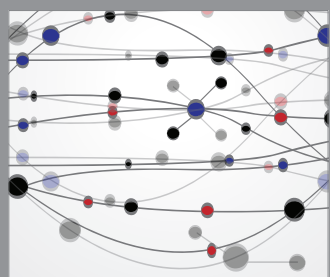

The Scientific World Journal
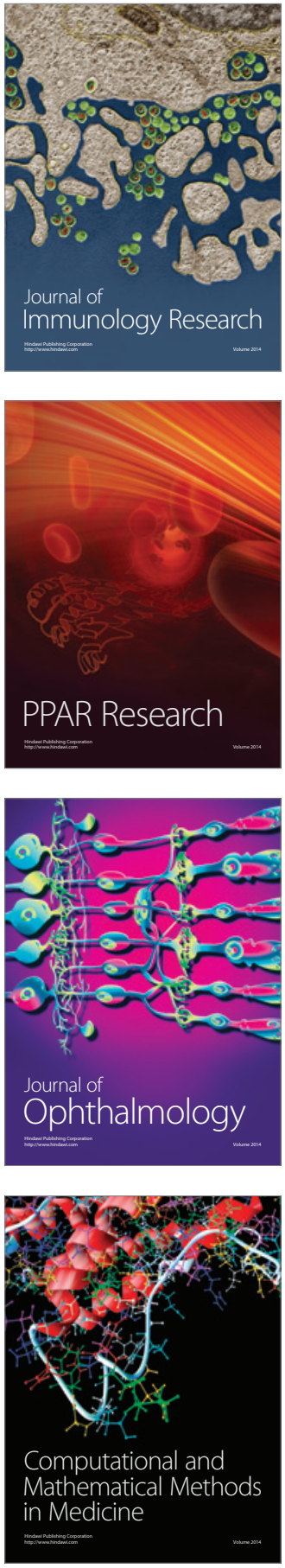

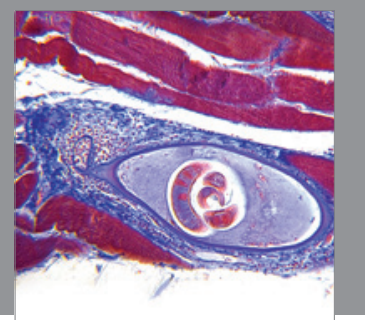

Gastroenterology

Research and Practice
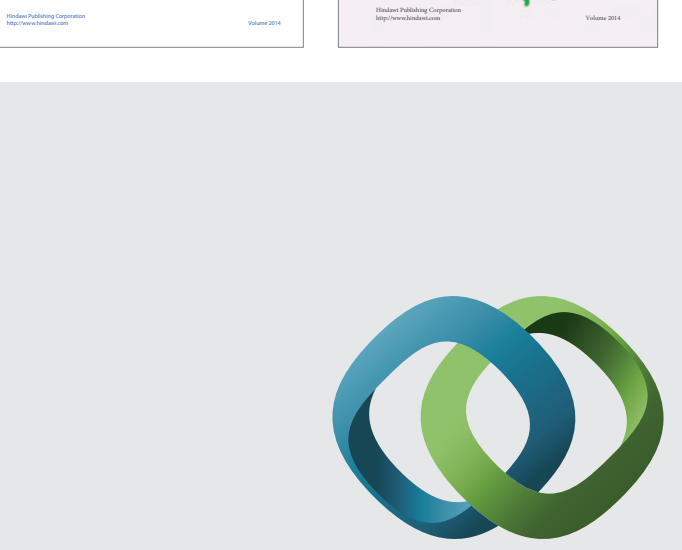

\section{Hindawi}

Submit your manuscripts at

http://www.hindawi.com
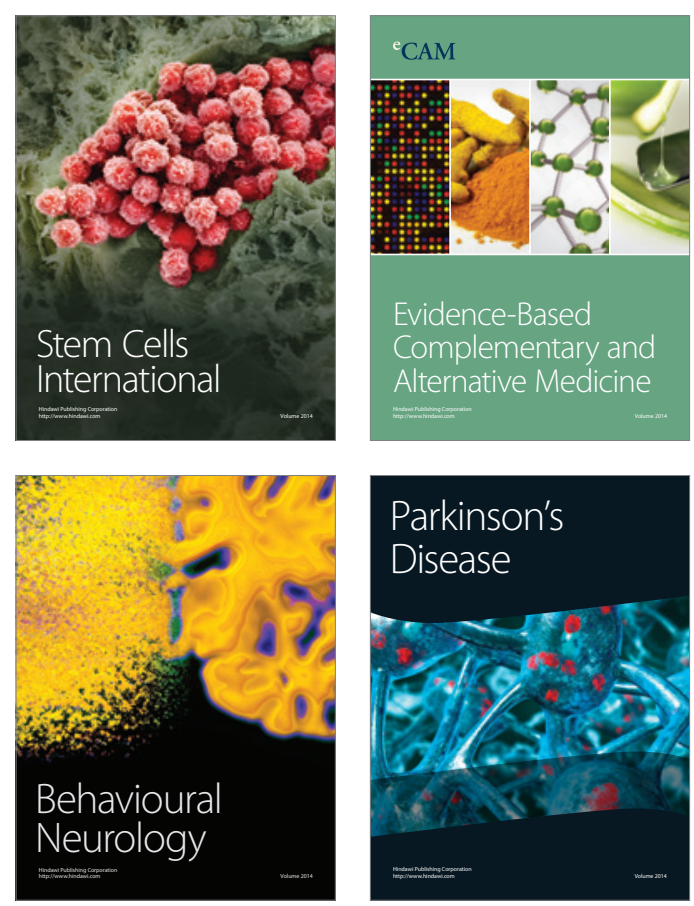

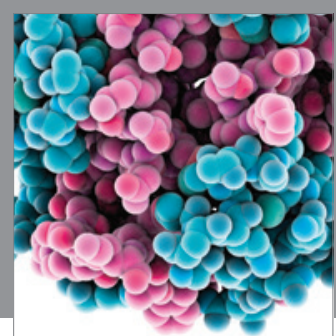

Journal of
Diabetes Research

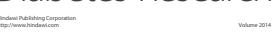

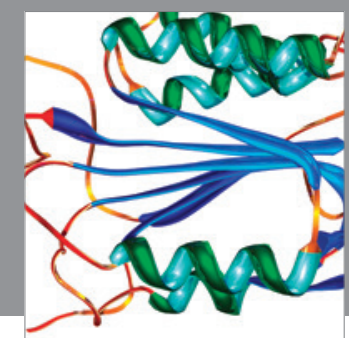

Disease Markers
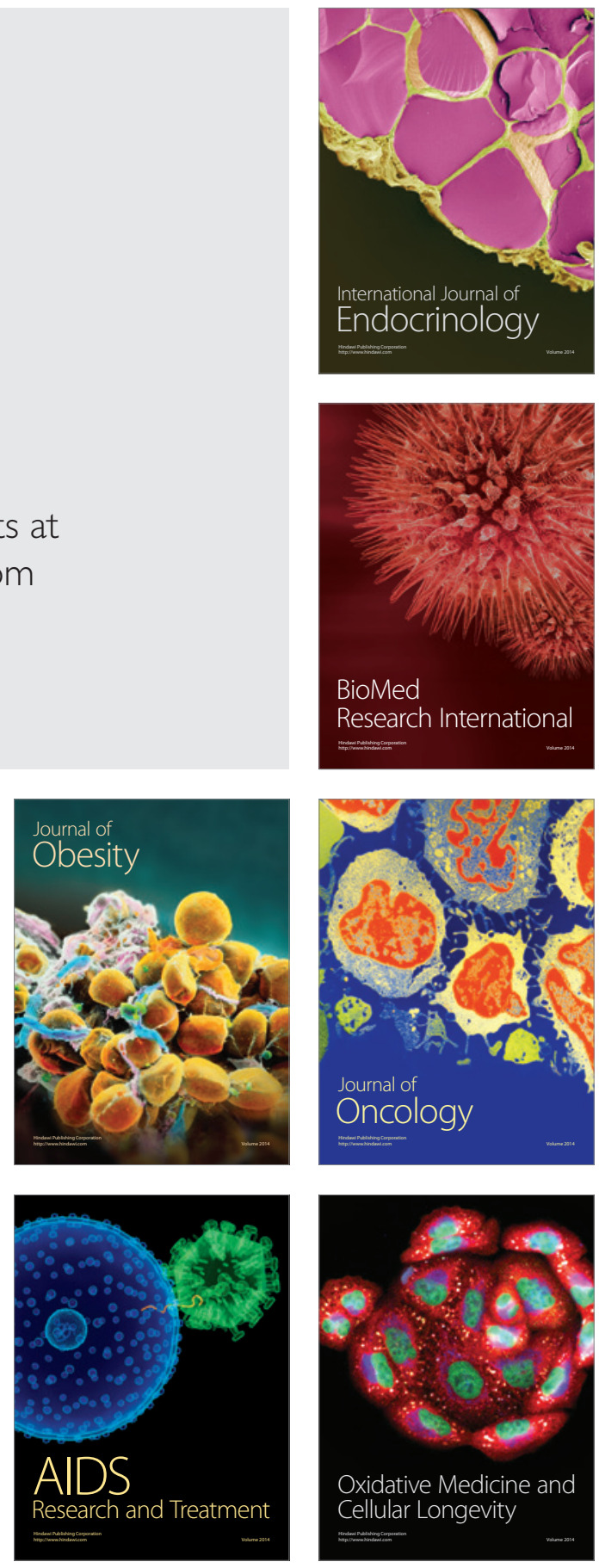